\title{
CONTABILIDADE AMBIENTAL: COMPLICAÇÕES ENFRENTADAS PELAS ORGANIZAÇÕES EM ADOTÁ-LA
}

Thais Rubia Ferreira Lepre, Irene Caires Da Silva, Helen Maira Santana, Larissa Lie lamabe Tsumuraya, Maicon Henrique De Oliveira, Victor Hugo De Almeida Coelho

Universidade do Oeste Paulista - UNOESTE, curso de Ciências Contábeis, Presidente Prudente, SP. E-mail: thaisrubia@unoeste.br

\section{RESUMO}

O estudo realizado analisa as dificuldades e as lacunas de informações presentes na Contabilidade Ambiental e explora alguns de seus principais conceitos e a sua contabilização, tendo como corpo beneficiário as empresas interessadas e a massa social. O objetivo dessa pesquisa é apresentar os obstáculos que as empresas ainda possuem ao adotá-la, visto que a maioria dos problemas apresentados é consequência da carência de informação, tratando-se de um tema extremamente importante e delicado. Foi utilizado para a realização da pesquisa a abordagem qualitativa, tendo como fonte de recursos e informações a pesquisa bibliográfica. Em suma, o artigo direciona os olhares para essa área pouco explorada com propósito de incentivar as empresas e a sociedade se envolverem no esquema e buscar maior conhecimento, dessa forma, o mercado poderá contar com maior número de profissionais, em contra partida, ter-se-á a gratidão da natureza.

Palavras-chave: Profissionalismo; Gestão Ambiental; Contador; Sustentabilidade; Conceitos Ambientais.

\section{ENVIRONMENTAL ACCOUNTING: DIFFICULTIES OF COMPANIES THE TO ADOPT}

\section{ABSTRACT}

The study analyzes the difficulties and gaps in the information present in Environmental Accounting and explores some of its main concepts and their accounting, having as a beneficiary body the companies interested and the society. The objective of this research is to present the obstacles that companies still have when adopting it, since most of the problems presented are a consequence of the lack of information, being an extremely important and delicate subject. The qualitative approach was used to carry out the research, having as a source of resources and information the bibliographic research. Concluding, the article directs the eyes to this unexplored area with the purpose of encouraging companies and society to get involved in the scheme and to seek greater knowledge, in this way, the market can count on a greater number of professionals, as a consequence, we have the gratitude of nature.

Keywords: Professionalism; Sustainable accounting; Counter; Sustainable; Environment Concept.

\section{INTRODUÇÃO}

Diante do exacerbado impacto causado à natureza - devido a ação humana - nas últimas décadas, é evidente, no atual momento, a importância que o termo "sustentabilidade" esta recebendo tanto das empresas quanto, principalmente, da sociedade. Tendo isso em vista, as organizações conscientes ampliaram seus extremos inserindo a questão do meio-ambiente em suas obrigações, tratando-a com a mesma relevância que os demais departamentos, a considerar: produção, finanças, recursos humanos, etc. 
A realização do gerenciamento ambiental requer a contribuição de diversos setores da empresa, sendo necessária a interação entre os diferentes âmbitos da organização, para garantir, com êxito, o funcionamento e a eficácia do processo.

No entanto, grande parte das organizações brasileiras ainda não optam pela contabilidade ambiental devido ao insuficiente conhecimento em relação ao assunto, ou seja, não sabem o que e como fazer para que a gestão ambiental esteja vigente na empresa.

Diante deste cenário, o presente artigo tem como problemática: Quais as dificuldades que as empresas possuem em adotar a Contabilidade Ambiental?

$\mathrm{O}$ artigo tem como objetivo apontar as dificuldades das empresas em adotar a Contabilidade Ambiental.

Deparando com tais problemas e impactos em relação a, principalmente, natureza, tornase imprescindível mensurar os impactos ambientais, através de uma administração eficaz, proveniente do processo produtivo de uma empresa, onde se torna possível visualizar vantagens competitivas e identificar oportunidades estratégicas, sendo integrada assim, de fato, a chamada Contabilidade Ambiental.

O presente estudo mostra-se importante pelo fato de expor o conhecimento e discutir acerca da Contabilidade Ambiental e sua contabilização tendo como corpo beneficiário as empresas interessadas e a massa social.

\section{METODOLOGIA}

A abordagem adequada a este artigo, considerando o objetivo traçado é a qualitativa, por possibilitar a descrição e analise das variáveis em estudo, além da explicação de suas relações (GOMES, 2007).

E coerentemente com esta abordagem, o método de coleta de dados utilizado foi a pesquisa bibliográfica, que "[...] é um apanhado geral sobre os principais trabalhos já realizados, revestidos de importância por serem capazes de fornecer dados atuais e relevantes relacionados com o tema" (MARCONI; LAKATOS, 2010, p. 142), que neste caso consistiuno uso de livros e artigos científicos que abordam o assunto pesquisado.

\section{RESULTADOS}

A Contabilidade Ambiental é um tema delicado para as organizações ainda, visto que sua evidência veio à tona somente nos últimos 10 anos. Além disso, o mercado não conta com mão de obra capacitada para tal desenvolvimento, o que dificulta ainda mais a inserção das empresas nesse novo parâmetro.

Segundo uma pesquisa realizada por Manterdal(2012) de uma amostra de contadores no mercado de trabalho, apenas 4,76\% dos profissionais contábeis cursaram disciplina de Contabilidade/Gestão Ambiental. Nesse caso, em 2012, mais de 95\% dos profissionais contábeis afirmaram ter pegado o diploma sem conceito algum do que realmente seja e o que abrange o tema de Contabilidade e Gestão Ambiental. Assim, as instituições de ensino, precisam rever os conceitos formados na mente do futuro profissional antes de formá-lo e lança-lo no mercado.

Ainda segundo a pesquisa, cerca de $43 \%$ dos questionados julgaram seu autoconhecimento insuficiente a respeito do tema, somente $1,52 \%$ julgaram-se ter um conhecimento excelente. Os demais julgaram-se com autoconhecimento Suficiente $(5,2 \%)$, Regular $(21,65 \%)$ e pouco suficiente (29,22\%). Dessa forma, é notória a carência de profissionais com visão sustentável no mercado de trabalho.

Segundo Vellani e Ribeiro (2009) para cada 100 quilos de material que entra no processo industrial somente 12 quilos representa o produto final, ou seja, 88 quilos correspondem a resíduos liberados da seguinte forma: 29 quilos em forma gasosa, 43 quilos em resíduos sólidos e 
16 quilos em forma líquida. É necessário que, além da destinação certa para esses resíduos, a organização possa reaproveitá-los de forma sustentável.

Em suma, é notável que o mercado conta com pouquíssimos profissionais qualificados para implementar uma política ambiental na organização. Com isso, a sociedade, as organizações e o Meio Ambiente sentem a carência deste comportamento.

Há um alto grau de importância para uma empresa adotar tal política, embora a dificuldade seja certa, mas, evidentemente, a oportunidade de se tornar uma empresa em proeminênciaé evidente. Além disso, o mercado passou a exigir esse rótulo das organizações, como Cardoso (2016, p.06) pondera:

Quem exige essa concepção das empresas? É o cliente que conquista novo espaço no processo produtivo? Antes adquiriam produtos apenas para satisfazer suas necessidades, atualmente exigem produtos ecologicamente corretos. Manifestações contra a compra de produtos de empresas irresponsáveis socialmente são divulgadas rapidamente, e os reflexos originados dessas manifestações populares acabam impondo a elas a prática do papel social.

Sendo assim, devido à exigência do mercado consumidor, as organizações precisam direcionar a atenção para esse movimento. Hoje, o cliente, além de requerer um produto de qualidade, também exige-se que sua origem seja de uma procedência sustentável. Além disso, a empresa que adota tal conduta adquire um diferencial no mercado, ganhando vantagens e se destacando das demais.

\section{DISCUSSÃO}

O Cenário atual, tratando da capacidade técnica dos profissionais contábeis, tende a ser melhor que o de 2012. Já é possível identificar as grades acadêmicas se aprimorando para atenderem a demanda do mercado. A pesquisa de Manterdal caso hoje aplicada nos mostraria uma queda significativa nos 95 pontos percentuais de ignorância técnica observada a cinco anos atrás.

Nota-se também, a corrida das organizações pela adoção de políticas de reaproveitamento de resíduos, uma vez que, o que antes fora descartado passou a ser utilizado para geração de energia. Além disso, conta-se também com a logística reversa e os programas de coletas seletivas. Sendo assim, a conjuntura exposta por Vellani e Ribeiro em 2009 é distinta do quadro contemporâneo.

Devido ao uso irresponsável dos recursos naturais, e visando o equilíbrio ecológico do planeta, manifestações de grupos que priorizam o interesse da sociedade para com o meio ambiente tornam-se mais intensas, como consequência disso, as organizações em âmbito mundialcomeçaram a tomar providências, visando a sustentabilidade, por meio da regularização de suas atividades, de forma que os impactos negativos na natureza sejam reduzidos (RIBEIRO, 2010).

Evidentemente que hoje um dos maiores problemas das organizações é a falta de harmonia entre financeiro e ecológico, por conta disso, muitas empresas possuem receio em adotar a gestão ambiental, pois acreditam que seja um desembolso sem retorno.

De modo que, tudo nas organizações precisa ser contabilizado, os investimentos ambientais não são diferente, para isso existe um ramo especifico da contabilidade denominado contabilidade ambiental que arrebata esse procedimento técnico .

De acordo com Ferreira (2011, p.53), "O desenvolvimento da Contabilidade Ambiental é resultado da necessidade de oferecer informações adequadas às características de uma gestão 
ambiental". Em suma, contabilidade ambiental se originou da necessidade de expor as informações das atividades executadas em prol da gestão ambiental.

Consequentemente a Contabilidade Ambiental é um mecanismo de informação com objetivo benéfico para as Organizações como afirma Ferreira (2011, p. 53)

É importante frisar que Contabilidade Ambiental não se refere a uma nova contabilidade, mas a um conjunto de informações que relatem adequadamente, em termos econômicos, as ações de uma entidade sobre o meio ambiente que modifiquem seu patrimônio. Esse conjunto de informações não é outra contabilidade, mas uma especialização.

Sendo assim, vale ressaltar que a contabilidade ambiental não é um novo tipo de contabilidade, mas um apanhado de informações sobre atividades executadas pela entidade, relacionadas com o meio ambiente, que são acrescidas no patrimônio da empresa.

De acordo com os estudos de Kraemer (2001, p.38):

Contabilidade Ambiental é a contabilização dos benefícios e prejuízos que o desenvolvimento de um produto, ou serviço, pode trazer ao meio ambiente. E um conjunto de ações planejadas para desenvolver um projeto, levando em conta a preocupação com o meio ambiente.

Portanto a contabilidade ambiental se relaciona com a contabilização dos benefícios e prejuízos causados pela produção de um produto, ou serviço, analisando seus impactos ao meio ambiente. São ações planejadas pela organização, visando sempre a preocupação com a natureza.

É de fato um grande problema para as organizações que adotam a gestão ambiental, distinguir o que é por exemplo: um lucro ou gasto com operações ambientais e os que são de atividades cotidianas da empresa, e para que isso não ocorra é necessário que a organização adote meios de relatórios, pelos quais são separados as atividades diárias normais da empresa, das atividades ambientais.

Ela se propõe a apresentar o relato ambiental de forma destacada nas demonstrações contábeis, portanto, sua implementação depende da definição de uma política contábil que considere a segregação dos itens relativos aos impactos ambientais das atividades da empresa no meio ambiente, prevendo, por exemplo, que os custos ambientais devem ser apresentados de forma segregada, desdobrados em itens de natureza operacional e não-operacional, e em itens recorrentes e extraordinários. (KREAMER, 2001, p.38).

Entretanto é de extrema importância as demonstrações das atividades ambientais, para que a empresa tenha controle do que ocorre e vem ocorrendo, tendo visão ampla sobre quais serão os custos relacionados com a atividade ambiental assegurando assim correções e controle da mesma. Outra dificuldade das empresas é realizar o isolamento das contas relacionadas as atividades ambientaiscom as das cotidianas da organização como, por exemplo, a criação em sua estrutura de plano de contas, contas relacionadas com meio ambiente como:o ativo, o passivo, os custos, as perdas e as receitas ambientais.

O Ativo Ambiental tem a mesma linha de raciocínio do ativo normal, são todos os bens e direitos que a organização possui e que se dirijam a preservação da natureza. Segundo Ribeiro (2010, p.61), "os ativos ambientais são constituídos por todos os bens e direitos possuídos pelas empresas, que tenham capacidade de geração de benefício econômico em períodos futuros e que visem à preservação, proteção e recuperação ambiental". 
Sendo assim, ativos ambientais são todos bens e direitos que a organização possui, que resultam no cultivo econômico futuro, tendo como objetivo, a prevenção, amparo, recuperação da natureza.

No Passivo Ambiental é contabilizado todas as obrigações que a empresa adquiri em prol da preservação da natureza. De acordo com Sperandio, Trindade e Favero (2005), pode-se afirmar que o passivo ambiental representa as obrigações relacionadas à preservação, recuperação e proteção do meio-ambiente, objetivando a comparabilidade entre o desenvolvimento econômico e o equilíbrio ecológico.

Portanto, tende-se como um passivo ambiental, qualquer forma de obrigação que a empresa contrai e que tenha analogia ao benefício do meio ambiente, seja em sua preservação, recuperação ou proteção.

Os Custos Ambientais podem ser vistos como cooptação dos benefícios que a organização busca alcançar com os investimentos em prol do meio ambiente, no arrefecimento da poluição recorrente ao processo de produção, esses custos são necessários para a obtenção de receitas futuras. É importante lembrar que os Custos Ambientais não são somente resultados dos investimentos diretos para o benefício de meio ambiente, estão incluídos, também, os custos indiretos para o objetivo da preservação da natureza. Para Ribeiro (2010), entre os custos indiretamente relacionados aos benefícios do período em curso, estão:

\section{Quadro 1: Custos indiretos}

- Administração do controle ambiental, custos de adequação do processo operacional e de auditoria;

- Treinamento;

- Pesquisas que não podem ser associadas com benefícios futuros específicos, iniciadas com o objetivo de prevenir e reduzir danos ao meio ambiente;

- Programas de reciclagem.

Fonte: Ribeiro (2010)

Citamos alguns exemplos desses custos na área operacional:

\section{Quadro 2: Exemplos}

Investimentos ambientais de natureza permanente:

- Custos de depreciação de maquinas e equipamentos antipoluentes;

Custos ambientais operacionais:

- Horas de mão de obra;

- Horas-máquina;

- Depreciação;

Fonte: Ribeiro (2010)

Pode-se observar que o Custo Ambiental não tem só relação direta, mas também de forma indireta e esses investimentos são indispensáveis para que o processo de colaboração com o meio ambiente funcione de forma adequada, como os itens citados a cima.

Como em todo processo de investimento sempre há riscos de perdas epara Ribeiro (2010, p.57), as Perdas Ambientais são:

As perdas refletem os gastos incorridos sem uma contrapartida em benefícios. Portanto, perdas ambientais são os gastos que não proporcionam benefícios para a empresa. Podem ser classificadas como normais ou anormais. Normais são aquelas previsíveis e de montantes previamente definidos como aceitáveis. Já as anormais são as inesperadas e de volume relevante. 
Com base no exposto, as perdas ambientais são consequências de um gasto realizado pela organização que não teve benefícios, essas perdas são classificadas como normais e anormais: as normais são acentuadas como admissíveis e as anormais são imprevisíveis e de grande volume.

Já as Receitas Ambientais podem ser os resultados tanto da diminuição do consumo de água e energia, quantodo retorno de valores superiores que ultrapassem os custos dos investimentos realizados pela empresa para pratica das atividades, que tem por objetivos a preservação da natureza (SANTOS; SOUZA, 2015).

\section{CONCLUSÃO}

O grande problema em relação ao desinteresse das organizações na adoção desse modo de gestão está na ausência de informação, visto que os profissionais se formam com pouco conhecimento no assunto, como ressaltado na pesquisa. Sendo assim, é necessário que os cursos como ciências contábeis, administração, engenharia ambiental, entre outros que estão ligados a gestão ambiental - mesmo que de forma indireta - foquem nessa área, pois os recursos que a natureza oferece para a produção de bens para circulação, infelizmente, são escassos.

Portanto, visto que a sustentabilidade se tornou um tema importante na atualidade, é primordial que a organização acompanhe o ritmo evolutivo do mercado moderno - no caso, a implementação da Contabilidade Ambiental - para que seja capaz de se manter no mesmo. Porém, esse tema ainda é muito sucinto, tanto em estudos quanto em sua aplicabilidade, sendo necessária a expansão do conhecimento nessa área para que os empresários possam tirar proveito. É fundamental que o gestor amplie seus horizontes e não vise somente o lucro, mas também, o desenvolvimento sustentável; através da Contabilidade Ambiental é possível que a organização se diferencie e ganhe vantagens em seu negócio, auferindo seus objetivos e gerando o bem-estar a sociedade.

\section{REFERÊNCIAS BIBLIOGRÁFICAS}

FERREIRA, A. C. S. Contabilidade Ambiental: uma informação para o desenvolvimento sustentável. 3. ed. São Paulo: Atlas, 2011.

GOMES, R. Análise e interpretação de dados de pesquisa qualitativa. In: MINAYO, M. C. de S (Org.). Pesquisa social: teoria, método e criatividade. 26. ed. Petrópolis: Vozes, 2007. p. 79-107.

KRAEMER, M. E. P. Contabilidade Ambiental: o passaporte para a competitividade. Revista Catarinense da Ciência Contábil, v. 1, n. 1, p. 15-40, 2001. Disponível em: <http://www.spell.org.br/documentos/ver/33597/contabilidade-ambiental-o-passaporte-para-acompetitividade>. Acesso em: 25 mar. 2017.

MANTERDAL, A. et al. Contabilidade Ambiental: nível de conhecimento dos profissionais contábeis da grande Florianópolis. Disponível em: <http://periodicos.uem.br/ojs/index.php/Enfoque/article/view/14303>. Acesso em: 15 abr. 2017.

MARCONI, M. A.; LAKATOS, E. M. Metodologia do trabalho científico. São Paulo: Atlas, 2010.

RIBEIRO, M. S. Contabilidade Ambiental. 2. ed. Saraiva, 2010. Disponível em: <https://integrada.minhabiblioteca.com.br/books/9788502108837/pageid/0>. Acesso em: $10 \mathrm{abr}$. 2017.

SANTOS, L. P. R.; SOUZA, L. D. Contabilidade Ambiental: uma contribuição da ciência contábil à sustentabilidade da gestão ambiental. Disponível em: 
<http://www.aems.edu.br/conexao/edicaoanterior/Sumario/2014/downloads/2014/Contabilidad e\%20Ambiental\%20Uma\%20Contribui\%C3\%A7\%C3\%A30\%20Da\%20Ci\%C3\%AAncia\%20Cont\%C3\% A1bil\%20\%C3\%80\%20Sustentabilidade\%20Da\%20Gest\%C3\%A30\%20Ambiental.pdf>. Acesso em: 20 mar. 2017.

SPERANDIO, L. A.; TRINDADE, M.; FAVERO, H. L. Uma introdução à discussão do passivo ambiental. Enfoque Reflexão Contábil, v. 24, n. 2, p. 5-18, 2005. Disponível em: <http://www.spell.org.br/documentos/ver/41823/uma-introducao-a-discussao-do-passivoambiental>. Acesso em: 23 fev. 2017.

VARELA, P. S.; COSTA, R. R.; DOLABELLA, M. M. Balanço Social: demonstrativo da função social da empresa. Contabilidade Vista \& Revista, v. 10, n. 2, p. 28-35, 1999. Disponível em: $<$ http://www.spell.org.br/documentos/ver/25113/balanco-social--demonstrativo-da-funcaosocial-da-empresa>. Acesso em: 20 mar. 2017

VELLANI, C. L.; RIBEIRO, M. S. Sustentabilidade e Contabilidade. Disponível em: <https://periodicos.ufsc.br/index.php/contabilidade/article/view/2175-8069.2009v6n11p187>. Acesso em: 20 mai. 2017. 